Đordano Peršurić

Ana Peršurić

Katarina Peršurić Bernobić
UDK: 663.2(497.5)

DOI: http://doi.org/10.21857/m16wjcpdw9

Izlaganje sa znanstvenog skupa

Rukopis prihvaćen za tisak: 14.9.2016.

\title{
PJENUŠAVA VINA U FUNKCIJI RAZVOJA VINARSTVA I KULTURE STOLA U REPUBLICI HRVATSKOJ
}

\begin{abstract}
Sažetak
Tehnologija proizvodnje prirodnih pjenušavih vina metodom vrenja u boci predstavlja najzahtjevniju tehnologiju u vinarskoj proizvodnji. Za proizvodnju pjenušaca upotrebljavaju se standardne svjetske sorte: Chardonnay, Pinot crni i Pinot Meunier u Champagni (Francuska), dok se u ostalim dijelovima svijeta, osim ovih koriste i brojne druge, vrlo često i autohtone sorte.

Potrošnja pjenušavih vina u svijetu i u EU, bitna je kako količinski, tako još više vrijednosno i u stalnom je porastu, dok je u Republici Hrvatskoj ona još uvijek skromna i količinski i vrijednosno, ali ima trend stalnog rasta.

Posljednjih godina broj proizvođača pjenušavih vina u velikom je porastu u svim vinogradarskim krajevima Hrvatske. Potrošnja tih vina u Hrvatskoj je daleko ispod potreba kod domaćih potrošača, ali i mogućnosti ponude u turizmu. Postojeća mala potrošnja trenutno se većim dijelom bazira na jeftinijim i po kvaliteti skromnim pjenušcima i gaziranim vinima iz uvoza.

Kultura pijenja kvalitetnih pjenušavih vina sastavni je dio kulture stola i življenja u razvijenim zemljama. Za očekivati je da će i u Hrvatskoj s podizanjem životnog standarda stanovništva i podizanjem kvalitete ugostiteljsko-turističkih usluga bitno rasti i potrošnja kvalitetnih pjenušavih vina. Zato se može tvrditi da u Hrvatskoj neće ni biti velikog napretka u razvoju vinarstva, bez segmenta potrošnje kvalitetnih pjenušavih vina, što otvara veliku razvojnu perspektivu i domaćim proizvođačima.
\end{abstract}

Ključne riječi: pjenušava vina; vinogradarstvo; potrošnja vina; kultura stola; klasična metoda.

\section{Uvod}

Pjenušava vina, po definiciji su vina dobivena prvim i drugim alkoholnim vrenjem svježeg grožđa, mošta od grožđa i vina (različitih kategorija kvalitete), koja kada se otvori posuda, otpuštaju ugljični dioksid, koji potječe isključivo od vrenja i ima 
tlak od najmanje 3 bara kao posljedicu otopljenog ugljičnog dioksida pri temperaturi zatvorene posude od $20^{\circ} \mathrm{C}$.

Šampanjac (francuski vin de Champagne), kako se često kod nas zove pjenušavo vino, je samo pjenušavo vino koje se proizvodi naknadnim (drugim) vrenjem u boci u francuskoj pokrajini Champagni i danas je taj naziv rezerviran isključivo za pjenušce iz te pokrajine. Pjenušava vina proizvedena u ostalim pokrajinama Francuske i u ostalim zemljama svijeta mogu se zvati samo pjenušci (Vin mousseux).

Tehnologija proizvodnje prirodnih pjenušavih vina metodom vrenja u boci predstavlja najzahtjevniju tehnologiju u vinarskoj proizvodnji. Za proizvodnju pjenušaca upotrebljavaju se standardne svjetske sorte: Chardonnay, Pinot Noir i Pinot Meunier u Champagni, dok se u ostalim dijelovima svijeta, osim ovih koriste i brojne druge, vrlo često i autohtone sorte.

Pjenušci zauzimaju oko $9 \%$ ukupne potrošnje vina u EU, dok je taj udio u Hrvatskoj znatno manji i iznosi tek oko $1 \%$ (OIV, Zavod za statistiku). Iako pjenušci bitno zaostaju za mirnim vinima po obimu proizvodnje i potrošnje, očekuje se da će svjetska potrošnja pjenušaca u narednim godinama rasti brže nego potrošnja mirnih vina. Predviđanja su da će potrošnja bitno rasti u zemljama poput SAD-a, Njemačke, Kine, Rusije i Australije, ali će njihova potrošnja padati u tradicionalno vinskim zemljama poput Francuske, Italije i Španjolske (www.jatrgovac.hr).

\section{Potrošnja pjenušaca u svijetu}

Prema OIV-u (2013.), u svjetskoj potrošnji vina pjenušci sudjeluju sa 6,6\% po količini, no po vrijednosti sudjeluju s čak $20 \%$ ukupne vrijednosti vina na svjetskom tržištu. Godine 2013. tržište pjenušavih vina vrijednosno je iznosilo 4. 373,7 milijuna $€$, što je rast od $1 \%$ u odnosu na 2012. godinu. Količinski se u svijetu ukupno prodalo 649,8 milijuna litara pjenušaca, što je porast od $3,4 \%$ u odnosu na 2012. Iz toga je vidljivo da su u 2013. pjenušci imali prosječno niže cijene nego u 2012., no to smanjenje nije utjecalo na snižavanje cijena u najvažnijim šampanjskim regijama svijeta (Francuska, Italija i Španjolska). U Italiji su se cijene pjenušaca povećale za 3,9\%, Francuskoj $0,9 \%$, a Španjolskoj 1,2\%. Unatoč rastu cijena od 3,9\% u Italiji je cijena pjenušaca (posebice Prossecco) niža nego u Francuskoj, zato je došlo do naglog povećanja prodaje talijanskih pjenušaca (Prossecco) uz rast u količinama i vrijednosti od 27\% (podatak objavljen na starnicama OIV-a, a preuzet od ISMEA).

Podaci o najvećim svjetskim uvoznicima pjenušaca prikazani su u tablici 1. 
Tablica 1. Najveći svjetski uvoznici pjenušaca u 2013. godini

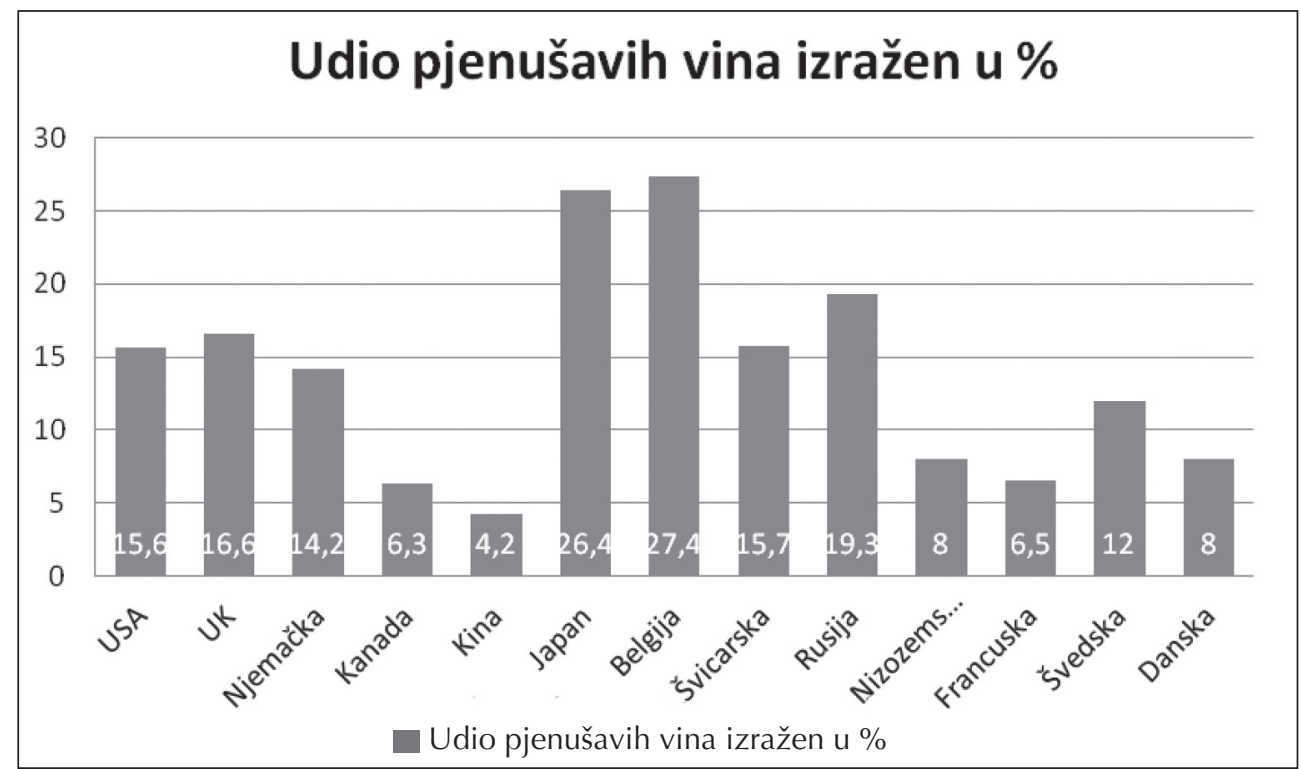

Napomena za podatke u tablici 1.: postotak označava udio pjenušaca u ukupno uvezenoj količini vina u tu zemlju tijekom 2013. godine.

Pet najvećih vinskih tržišta u svijetu u 2013. godini (OIV) su :

1. Ujedinjeno Kraljevstvo - uvoz skupljih i jeftinijih vina ostao je gotov jednak kao i u 2012. Uvezeno je pjenušaca u vrijednosti 822,4 milijuna američkih dolara, odnosno 83,6 milijuna litara.

2. Sjedinjene Američke Države - povećali su uvoz skupljih i kvalitetnijih vina, a smanjili uvoz jeftinijeg vina. Uvezeno je pjenušaca u vrijednosti 822,1 milijuna američkih dolara, odnosno 76,8 milijuna litara.

3. Njemačka - smanjila je uvoz pjenušaca u količinama i kvaliteti za 6,7\%. Uvezeno je pjenušaca u vrijednosti 442,5 milijuna američkih dolara, odnosno 73,8 milijuna litara.

4. Kanada - povećala je uvoz kvalitetnih vina i pjenušaca. Uvezeno je pjenušaca u vrijednosti 116,5 milijuna američkih dolara, odnosno 11,6 milijuna litara.

5. Kina - drastično se povećala količina uvezenih pjenušaca, ali po znatno nižim cijenama.

Uvoz pjenušaca u količinama veći je za 38,0\%, a iznosi 8,7 milijuna litara, ali vrijednost uvezenih pjenušaca iznosila je 64,7 milijuna američkih dolara.

Od 2000. do 2012. godine količine prodanih pjenušaca u svijetu nisu se bitno mijenjale. Prosječno se godišnje proda oko $17 \%$ od ukupne vrijednosti prodanog vi- 
na (uključuje mošt, rinfuzu i buteljirana vina). Najveći su udio pjenušci imali 2008. $(19,9 \%)$, a najmanji 2001. (15,4\%). U 2012. godini udio pjenušaca po vrijednosti iznosio je $17,1 \%$, a 2013. 20,0\%. U 2012. godini 11 najvažnijih izvoznika izvezlo je pjenušaca ukupne vrijednosti 3.761,0 milijuna $€$, odnosno 571,1 milijuna litara (OIV).

\section{Pjenušava vina u Republici Hrvatskoj, stanje i mogućnosti proizvodnje i potrošnje}

U Hrvatskoj se ne vode posebno statistički podaci o proizvodnji niti o potrošnji pjenušavih vina. Međutim kod godišnjih izvješća o proizvodnji, otpremama i zalihama vina, koje proizvođači dostavljaju u carinsku upravu, nalaze se razdvojeni podaci o mirnim i pjenušavim vinima. Budući da nisu izdvojena gazirana vina, takvi su podaci beskorisni za analizu proizvodnje i potrošnje pjenušavih vina metodom vrenja u boci ili u tanku. Zato sigurnih podataka te vrste za objavu, ali i za vođenje bilo kakve politike, nemamo pa ćemo iznijeti samo dostupne.

Zavod za vinarstvo i vinogradarstvo je za 2008. godinu iznio podatak da je na tržište stavljeno manje od 10 vagona (100.000 litara) pjenušaca proizvedenih u Hrvatskoj. Tu nije definirano koliko je gaziranih vina, ali vjerojatno ih je bilo $70-80 \%$.

Zavod za statistiku 2009. godine bilježi da su bila registrirana 22 proizvođača pjenušavih vina u Hrvatskoj, od toga gotovo polovica iz okolice Zagreba. Navodi se da se većina bavi proizvodnjom pjenušaca klasičnom metodom.

Godišnja potrošnja pjenušaca u ukupnoj potrošnji vina u Hrvatskoj 2010. godine iznosila je 1,4\%. Prosječno se u Hrvatskoj popije manje od $2 \mathrm{dl}$ pjenušca po glavi stanovnika, a Francuzi i Nijemci prosječno popiju 5 i više litara godišnje. Bez obzira na ovako malu potrošnju po glavi stanovnika (oko 4 milijuna stanovnika) u Hrvatskoj se popije $8.000 \mathrm{hl}$ ili 1.07 milijuna boca od 0,75 lit. Koliko od toga popiju strani turisti, nema podataka, ali sigurno oko $50 \%$, pa se naša potrošnja svede na $1 \mathrm{dl}$ po glavi stanovnika. Od te naše potrošnje najviše se troše jeftina (i gazirana vina problematične kvalitete) koja i ne spadaju u kategoriju pjenušavih vina po sadašnjoj hrvatskoj i EU zakonskoj regulativi. Ovisno o godini, uvozimo 50-86\% svih vina s mjehurićima (Alpeza, Gašparec-Skočić, 2003).

U Hrvatskoj kao tradicionalno vinskoj zemlji, s obzirom na sadašnji mali udio potrošnje pjenušaca u ukupnoj potrošnji vina, za očekivati je da će pjenušava vina u narednim godinama zauzeti bitniju ulogu.

\section{PJENUŠCI I KULTURA STOLA}

Percepcija pjenušavog vina je da je ono „Kralj vina i vino za kraljeve“. Nastanak pjenušca veže se uz benediktinca Dom Pierra Perignona (1638. - 1715.) iz grada Epernaya u francuskoj pokrajini Champagni. Po brojnim podacima iz literature, ta- 
kva su se pića proizvodila i pila na bogataškim dvorovima Rimljana i u stoljeću prije Krista. U rimskom carstvu, Plinije je (77. prije Krista) odredio zemljopisnu zonu proizvodnje pjenušca, što je najstarija zaštita kontroliranog podrijetla vina (Alpeza, Gašparec-Skočić, 2003.). U to vrijeme pa sve do kraja 19. stoljeća, to je bila kultura stola i kultno piće bogatih, a ne za masovniju konzumaciju. Da je pjenušac važan dio u kulturi i životu pojedinaca, a posebice proizvođača pjenušaca i šampanjaca, najbolji je primjer odgovor gospođe Lily Bollinger, iz istoimene šampanjerije, na novinarsko pitanje: „Kada pije šampanjac? “ Ona je odgovorila: „Šampanjac pijem jedino kada sam sretna i kada sam žalosna. Ponekad ga pijem kada sam usamljena. Obavezno ga pijem kada imam društvo. Provodim vrijeme uz njega ako nisam gladna, a kad sam gladna pijem ga. Drugačije ga ne diram, osim ako nisam žedna."

Na osnovu stanja u Hrvatskoj i potrošnji pretežito gaziranih vina loše kvalitete, mi nećemo tako brzo podignuti našu kulturu stola kroz potrošnju dobrih pjenušavih vina. S obzirom na danas niski životni standard i malu kupovnu moć većine stanovništva, veću potrošnju možemo ciljano povezati s proizvodnjom prirodnih pjenušavih vina kod malih vinara i vinogradara. Prema podacima APPRRR od 7.10.2014. u Republici Hrvatskoj imamo 41.697 PG (poljoprivrednih gospodarstava) koji imaju prijavljene vinograde i 6.103 PG podnositelja izjava o proizvodnji vina. Proizvesti pjenušac u svojem podrumu, za sebe, svoju obitelj, prijatelje i mali obiteljski „biznis", bilo bi lijepo i prestižno. To bi bilo posebno bitno jer je tehnologija proizvodnje prirodnih pjenušavih vina metodom vrenja $u$ boci sam vrh tehnologija u vinarskoj proizvodnji pa bi se time podigli svi standardi u vinarstvu, od proizvodnje do potrošnje. Povećanjem ukupnog broja proizvođača, posebno onih iz hobija, uvelike bi se povećao krug poznavatelja, potrošača i ljubitelja pjenušaca (poput gospođe Bollinger), što bi bitno podignulo našu kulturu stola i življenja u cjelini.

Za proizvodnju pjenušaca upotrebljavaju se standardne svjetske sorte: Chardonnay, Pinot Noir i Pinot Meunier u Champagni (Francuska), dok se u ostalim dijelovima svijeta, osim ovih koriste i brojne druge, vrlo često i autohtone sorte. Zato naši mali vinari - „šampanjeri“, da bi bili u trendu, najbolje je da upotrebljavaju one bijele sorte koje imaju u svom vinogradu. Kod crnih sorata trebali bi upotrebljavati rose varijantu vina.

Primjeri godišnje potrošnje pjenušaca „ $\mathrm{M}^{\prime \prime}$ u nekim najvećim turističkim tvrtkama i restoranima (100 do 150 mjesta) u Istri, prema ostvarenim podacima proizvođačke tvrtke Pjenušci Peršurić d.o.o. Višnjan u 2013. godini:

- „Tvrtka A“ - 136 boca pjenušaca „M" (tvrtka troši oko 20.000 boca gaziranog vina),

- „Tvrtka B“ - 192 boce pjenušaca „,M“ (tvrtka troši oko 20.000 boca gaziranog vina),

- "Tvrtka C“ - oko 2.500 boca pjenušaca „M“", (prezentacije i obuka osoblja)

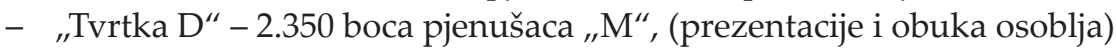


- Samostalni hotel sa oko 150 kreveta - oko 600 boca pjenušaca „M", (prezentacije)

- Restoran "A" - oko 800 boca pjenušaca "M",

- Restoran „B" -576 boca pjenušaca " $\mathrm{M}^{\prime \prime}$,

- Restoran „C $\mathrm{C}^{\prime \prime}-522$ boce pjenušaca " $\mathrm{M}^{\prime}$.

Na osnovu ovih podataka o potrošnji prirodnih pjenušavih vina lokalne tvrtke proizvođača, može se zaključiti da ovi primjeri dokazuju naše velike mogućnosti potrošnje u turizmu, u paketu s ponudom autohtonih enogastronomskih delicija. Dva primjera velikih tvrtki koje troše pretežito gazirana vina predstavljaju našu nisku kulturu stola, koju nažalost njihovi gosti prepoznaju, ali očito ne reagiraju jer te tvrtke dobro posluju. Rukovoditelji tih tvrtki, njihovi vlasnici i osobni gosti uvijek su počašćeni pravim pjenušcima, a najčešće pjenušcima „" $\mathrm{M}^{\prime \prime}$.

\section{PJENUŠAVA VINA - STANJE U HRVASTKOJ}

Kod nas postoji puno problema koji ograničavaju povećanje proizvodnje i potrošnje dobrih pjenušavih vina. Jedan od bazičnih problema predstavlja nedovoljna educiranost novih proizvođača o proizvodnji i prodaji pjenušaca kroz odgovarajući obrazovni sustav. Također nema primjerene edukacije ugostitelja i hrvatskih potrošača. Loš utjecaj na povećanje imaju velika potrošnja loših gaziranih vina što odbija potencijalne konzumente pjenušavih vina te veliki uvoz tih gaziranih vina, od kojih su mnoga deklarirana kao pjenušava vina proizvedena charmat metodom. Do zavaravanja konzumenata neispravnim deklariranjem gaziranih vina dolazi pak, jer u Hrvatskoj ne postoje efikasna kontrola za suzbijanje patvorenja pjenušavih vina i analize za utvrđivanje porijekla $\mathrm{CO} 2 \mathrm{u}$ pjenušcu. Svoj udio u neuspjehu širenja svakako imaju nedostaci primijenjenog istraživačkog rada o pjenušcima, udruženje koje bi se brinulo za status te proizvodnje u Republici Hrvatskoj i proizvođači specijalne opreme za male proizvodne pogone. Česta pojava je da proizvođači neprodano vino šampanjiziraju, stoga na tržištu imamo loših pjenušaca, koji damping cijenama otežavaju poslovanje pravim proizvođačima pa zbog neznanja, inercije ili nedostatka dobrih pjenušavih vina domaće proizvodnje, restorani većinom nude žestoko piće za aperitiv što umataju u našu tradiciju. Skupi kapital otežava poslovanje proizvođačima pjenušaca, jer ciklus proizvodnje traje 3-4 godine, pa se ulaganje u zalihe ne može naplatiti kroz cijenu. S druge strane postoji veliki broj konzumenata i ljubitelja koji zbog ekonomske krize, niskog životnog standarda, posebno ljudi starije životne dobi, nisu u mogućnosti konzumirati pjenušce i u najprimjerenijim trenucima za to. Osim vrlo visoke prodajne cijene koje najčešće formiraju u većini ugostiteljskih objekata, u korist potrošnje ne ide problematika vezana za slabo educirano osoblje, od neadekvatno pripremljenih čaša i/ili pjenušaca do potpunog nepoznava- 
nja te vrste proizvoda. Još jedan od problema s kojim se susreću proizvođači svakako su razne manifestacije u Republici Hrvatskoj na kojima pjenušce ocjenjuju slabi poznavatelji takvih proizvoda, na taj način proizvođači odbijaju slanje svojih proizvoda i umanjuju mogućnost promocije istih. Plasman hrvatskih pjenušaca u Europskoj uniji otežava nepotrebna i kompleksna administracija vezana za dokumentaciju potrebnu za izvoz u EU, nemogućnost elektronske najave i prijave izvoza u EU, postojanje trošarine i potrebe za trošarinskim skladištem za koja mali proizvođači koji rijetko izvoze najčešće nemaju mogućnosti organiziranja i stvara im dodatni trošak. Naša potpuna neorganiziranost i nesposobnost za brži iskorak $u$ razvoju općenito, $u$ ovoj proizvodnji tako dolazi do još većeg izražaja.

Uz probleme imamo i dobrih stvari ili njihovih naznaka. Veliki broj ozbiljnih proizvođača vina u svim vinogorjima započeli su sa stavljanjem na sekundarnu fermentaciju određene količine vina s ciljem proizvodnje pjenušca. Velika pomoć je i mogućnost unajmljivanja strojeva i stručnjaka iz inozemstva za sve procese u šampanjizaciji, a u nekim specijalističkim enološkim školama studenti već uče praktično proizvoditi pjenušce. Događaju se promjene i na polju edukacije ugostitelja koji već standardno nude pjenušce za aperitiv te se organiziraju kvalitetni tečajevi za sommeliere koji se na njima dobro educiraju o pjenušcima. Postoji porast potražnje jer je naša turistička klijentela naviknuta na tu vrstu proizvoda, a i blizina velikih gradova u susjednim zemljama, gdje se pjenušci standardno konzumiraju, su naša velika šansa.

\section{MOGUĆNOSTI I PERSPEKTIVE PROIZVODNJE I POTROŠNJE PJENUŠACA U REPUBLICI HRVATSKOJ}

Mogućnosti u proizvodnji i potrošnji pjenušavih vina kod nas, posebno najcjenjenijom metodom vrenja u boci, vrlo su velike u svim vinogradarskim podregijama. Upravo pretvaranjem agroekološki specifičnih karakteristika, vinogradarskih regija, podregija i vinogorja u fina i prepoznatljiva vina i prirodne pjenušce, naša je velika šansa, mogućnost i perspektiva. Veliki broj školovanih mladih vinskih stručnjaka i sommeliera sve veći broj domaćih ljubitelja i konzumenata pjenušaca, veliki broj turista, koji standardno troše takvu vrstu proizvoda, čine realnu osnovu za brži iskorak u proizvodnji i domaćoj potrošnji dobrih pjenušaca. Članstvo Republike Hrvatske u EU, uz eliminaciju sadašnjih nepotrebnih birokratskih prepreka otvorit će nam to veliko i bitno europsko tržište. Ali nije normalno da nudimo i prodajemo pjenušce u Europi i svijetu, a u Republici Hrvatskoj su hrvatski pjenušci kao proizvod vrlo slabo cijenjeni, gotovo pa beznačajni. 


\section{Zaključci i preporuke}

Kultura pijenja kvalitetnih pjenušavih vina sastavni je dio kulture stola i življenja u razvijenim zemljama, u kojima potrošnja ima trend povećanja. Za očekivati je da će i u Hrvatskoj s podizanjem životnog standarda i kupovne moći stanovništva te podizanjem kvalitete ugostiteljsko-turističkih usluga bitno porasti i potrošnja kvalitetnih pjenušavih vina. Najveće povećanje i ubrzanje potrošnje pjenušaca mogli bi ostvariti organiziranim i poticajnim mjerama proširenja proizvodnje kod malih OPG-a. Također, potrebno je kvalitetno povezivanje i organiziranje proizvođača pjenušaca, kako bi se izborili za rješavanje specifičnih problema u toj branši.

U Hrvatskoj neće biti većeg napretka u razvoju vinarstva bez segmenta potrošnje kvalitetnih pjenušavih vina, što otvara veliku razvojnu perspektivu malim domaćim proizvođačima vina u svim vinogorjima.

\section{Literatura}

Alpeza, Ivana, Gašparec-Skočić, Ljiljana (2003), Pjenušava vina, zanimljivosti proizvodnje i prometa. U: S. Bulimbašić (ur.), Zbornik radova Sabatina, Split, Zadružni Savez Dalmacije "Zadrugar", str. 74. - 87.

Alpeza, Ivana (2005.), Prošek, pjenušci,... Prigodna vina za prigodne dane, ali i prigodna vina za svaki dan. Glasnik zaštite bilja, 29 (6), str. 89. - 95.

APPRRR - Agencija za plaćanja u poljoprivredi, ribarstvu i ruralnom razvoju RH (2014), Tipologija PG-a, preuzeto sa: www.apprrr.hr/upisnik-poljoprivrednihgospodarstava

APPRRR - Agencija za plaćanja u poljoprivredi, ribarstvu i ruralnom razvoju RH (2014), Broj OPG-a prema spolu i godinama nositelja, preuzeto sa: $\underline{\text { www.apprr.hr/ }}$ upisnik-poljoprivrednih-gospodarstava

Aurand, Jean-Marie (2014.), State of World Vitiviniculture situation, 37 th World Congress of Vine and Wine, Argentina

Fočić, Nina, Brkić, Robert (2013.), Pjenušci-luksuzno i prigodno piće, Rubrika I\&A, preuzeto sa: www.jatrgovac.hr

International Organisation of Vine and Wine - OIV (2014.), OIV's Focus on the Sparkling wine marke. Statistical publications, The OIV's assessment of the world vitiviniculture situation, preuzeto sa: www.oiv.int/oiv/info/enpublicationsstati$\underline{\text { stiques }}$

Peršurić, Đordano (2002), Prirodna pjenušava vina - pića za sretne i vesele trenutke, Istarska Danica 2002, Izdavači: "J. Turčinović“ d.o.o. Pazin i IKD „J. Dobrila" Pazin 
Peršurić, Đordano (2014.), Proizvodnja prirodnih pjenušavih vina kod malih vinara, Vrtlar, 2 (7), str. 25. -28.

Pjenušci Peršurić d.o.o. (2014.), Podaci o prodaji za 2013. - arhiva

Zavod za statistiku (2010), Statistički podaci o potrošnji vina u RH

Zavod za vinarstvo i vinogradarstvo (2010.), Izvješće o aktionostima u 2010. Godini, preuzeto sa: www.hcphs.hr

\section{Sparkling Wines in Function of Viticultural Development and Table Culture in the Republic of Croatia}

\section{Summary}

The sparkling wines production technology based on the champagne method of fermentation in the bottle is top technology in wine production. For the production of sparkling wines, standard worldwide varieties such as Chardonnay, Pinot noir and Pinot Meunier (in Champagne, France) are used, while in other parts of the world, besides them, a number of local varieties are used as well.

The consumption of sparkling wines worldwide and in the EU is important in quantity and even more in quality, and is steadily growing, while in Croatia, the consumption is still modest in terms of quantity and quality, but with rising trends.

During the recent years, the number of the producers of sparkling wines in all viticultural regions of Croatia is on the rise. The consumption of these wines in Croatia is far below the needs and possibilities of the local inhabitants, as well as in tourist offer. The existing low power of consumption is currently based on cheap and lower-quality foreign sparkling wines.

The culture of drinking quality sparkling wines is a part of table culture and living standard in developed countries. It is to be expected that the rise of living standard in Croatia and the rise of the quality of gastronomy offer will enhance the consumption of quality sparkling wines. Therefore, we can claim that the consumption of sparkling wines will open a great development perspective for viticulture and domestic producers.

Keywords: sparkling wines; viticulture; consumption of wines; table culture.

Đordano Peršurić

Institut za poljoprivredu i turizam

K. Huguesa 8, 52440 Poreč

djordano@iptpo.hr

Ana Peršurić

Pjenušci Peršurić d.o.o.

Pršurići 5a, 52463 Višnjan

ana@misal.hr

Katarina Peršurić Bernobić

Pjenušci Peršurić d.o.o.

Pršurići 5a, 52463 Višnjan

katarina@misal.hr 